\title{
Clover-leaf artifact after successful percutaneous closure of muscular ventricular septal defect
}

\section{Artefacto de hoja de trébol después del cierre percutáneo exitoso del defecto del tabique ventricular muscular}

\author{
Mozhghan Parsaee ${ }^{1}$, Kamran Mohammadi ${ }^{1}$, Leili Pourafkari ${ }^{1,2}$ and Nader D. Nader ${ }^{2 *}$ \\ ${ }^{1}$ Echocardiography Research Center, Rajaie Hospital, Iran University of Medical Sciences, Tehran, Iran; ${ }^{2}$ Department of Anesthesiology, University \\ at Buffalo, Buffalo. New York, USA
}

A 25-year-old woman presented to our echocardiography laboratory for a follow-up imaging study. She had a history of muscular ventricular septal defect (VSD) closure by Amplatzer Muscular VSD Occluder (St. Jude Medical, USA) 4 years before this visit. Since this repair, she has remained asymptomatic and was on no medication. In transthoracic echocardiography, the double disc device was visualized in apical four-chamber view (Fig. 1) with no residual VSD flow. Interestingly, in off-axis view of parasternal long-axis imaging, the device was visualized in the form of two side-by-side figure of 8 "Clover-leaf" appearances (Figs. 2 and 3).

Percutaneous disc occluders due to their specific "epitrochoidal" mesh configuration and the interaction with ultrasound waves; form this image artifact when viewed from a coronal imaging position ${ }^{1}$. Transthoracic echocardiography is the main method of follow-up for post-procedural device position, and accurate interpretation of views is of utmost importance ${ }^{2}$.

By increasing utilization of percutaneous closure devices for various indications including atrial and VSD,

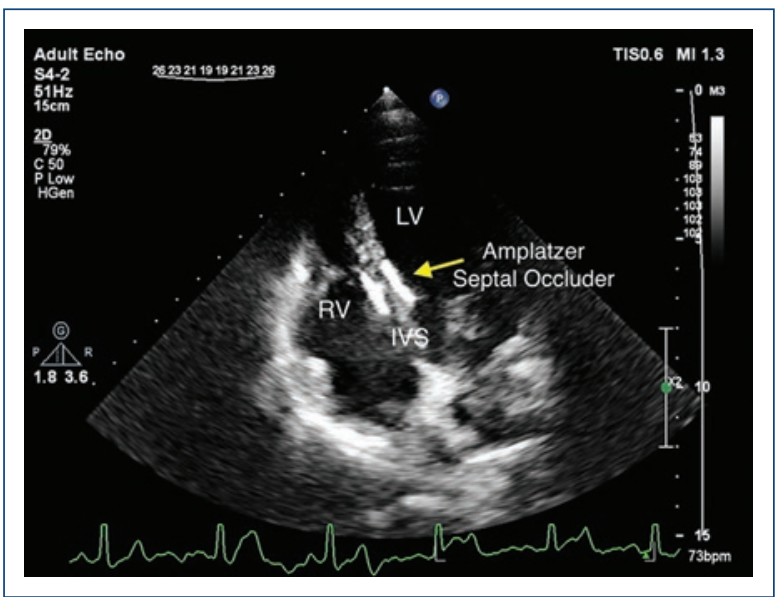

Figure 1/Video 1. Apical four-chamber echocardiogram showing normal biventricular function. The double-disc occluder device is visualized in the mid part of the interventricular septum.

left atrial appendage, patent foramen ovale, recognition of this particular pattern as a normal imaging artifact of a deployed double-disc device when visualized from a

\section{Correspondence:}

*Nader D. Nader

E-mail: nadernd@gmail.com
Date of reception: 02-10-2018

Date of acceptance: 12-11-2018

DOI: 10.24875/ACME.M19000011
Available online: 09-08-2019 Arch Cardiol Mex (Eng). 2019;89(1):70-71 www.archivoscardiologia.com 2604-7063 @ 2018 Instituto Nacional de Cardiología Ignacio Chávez. Publicado p
la licencia CC BY-NC-ND (http://creativecommons.org/licenses/by-nc-nd/4.0/). 


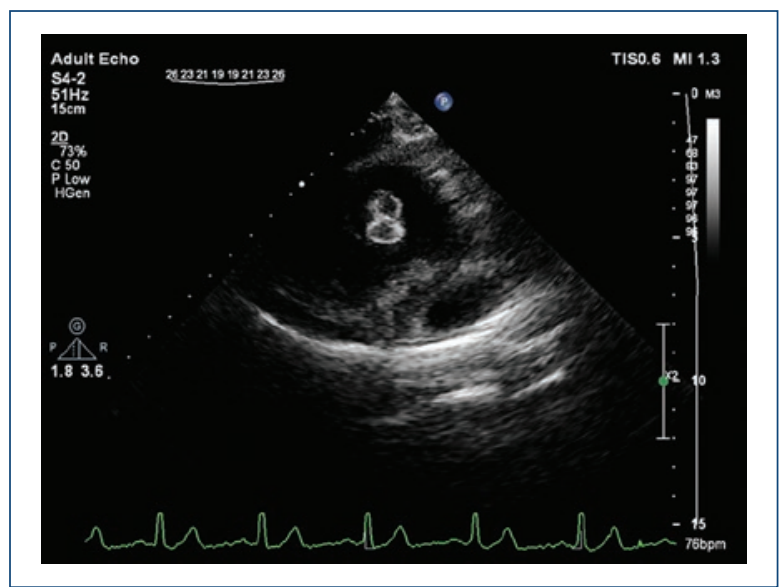

Figure 2/Video 2. Off-axis parasternal long-axis view showing the figure of 8 image artifact of the occluder device.

coronal imaging position is necessary to avoid misinterpretations of studies such as malposition or displaced device.

\section{Conflicts of interest}

The authors declare do not have conflicts of interest.

\section{Ethical disclosures}

Protection of human and animal subjects. The authors declare that no experiments were performed on humans or animals for this study.

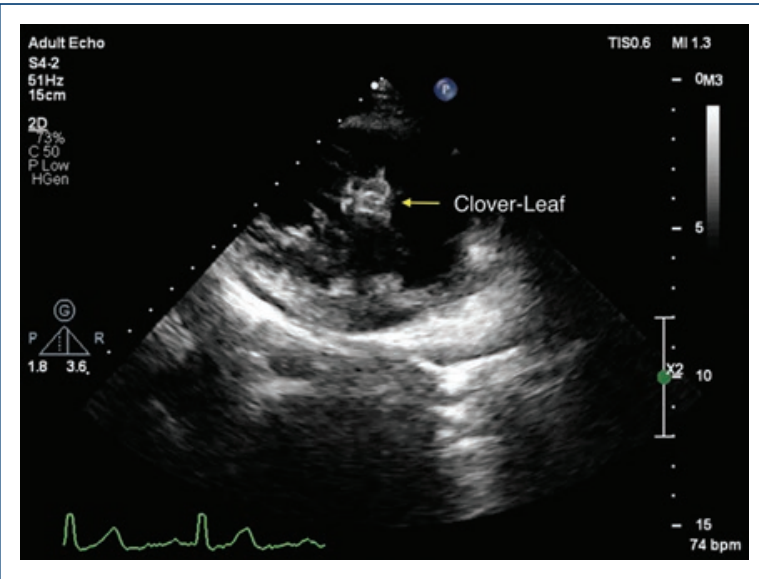

Figure 3/Video 3. The occluder device resembles a cloverleaf in this off-axis parasternal long-axis view.

Confidentiality of data. The authors declare that they have followed the protocols of their work center on the publication of patient data.

Right to privacy and informed consent. The authors declare that no patient data appear in this article.

\section{References}

1. Bertrand PB, Levine RA, Isselbacher EM, et al. Fact or artifact in two-dimensional echocardiography: avoiding misdiagnosis and missed diagnosis. J Am Soc Echocardiogr. 2016;29:381-91.

2. Bertrand PB, Grieten L, Smeets CJ, et al. The figure-of-eight artifact in the echocardiographic assessment of percutaneous disc occluders: impact of imaging depth and device type. Echocardiography. 2015;32:557-64. 